\title{
ERRATUM
}

\section{A population-based study of osteoporosis testing and treatment following introduction of a new bone densitometry service}

W. D. Leslie · L. MacWilliam • L. Lix • P. Caetano •

G. S. Finlayson

Published online: 4 May 2006

(C) International Osteoporosis Foundation and National Osteoporosis Foundation 2006

An incorrect version of Fig. 4 was supplied. The correct version of the figure is given here.
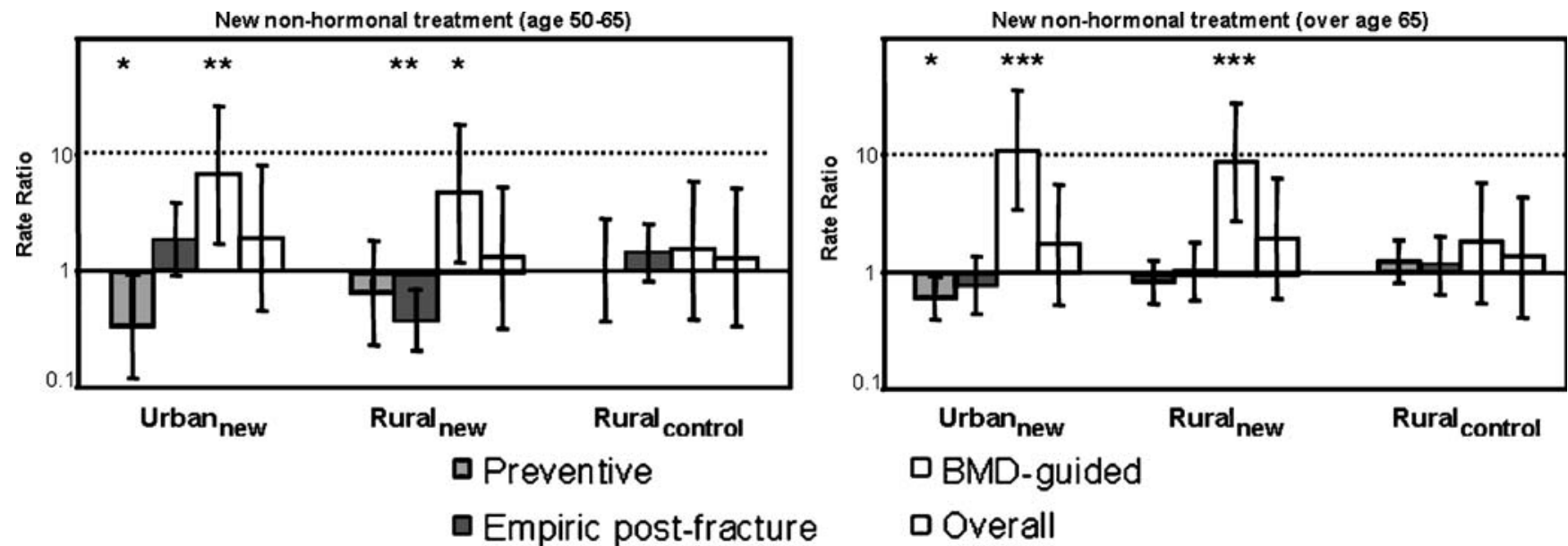

The online version of the original article can be found at: http://dx. doi.org/10.1007/s00198-004-1756-5.

W. D. Leslie $(\bowtie)$

Department of Medicine (C5121),

St. Boniface General Hospital,

409 Tache Avenue,

Winnipeg, R2H 2A6, Canada

e-mail: bleslie@sbgh.mb.ca

Tel.: +1-204-2372311

Fax: $+1-204-2337154$

W. D. Leslie · L. MacWilliam · L. Lix · P. Caetano ·

G. S. Finlayson

Manitoba Centre for Health Policy, Faculty of Medicine,

University of Manitoba,

Winnipeg, Canada 